\title{
Seismic Performance Evaluation of the Existing RC Frames Reinforced by Chevron Bracing System
}

\author{
Keunyeong Oh, Heonjun Ha, Byeonghyun Jo, Kangmin Lee \\ Dept. of Architectural Engineering, Chungnam National University \\ 99 Daehak-ro, Yuseong-gu, Daejeon, Korea
}

first.sniper7608@naver.com; second.gkgjswns1008@naver.com; third.hyeon7959@naver.com; fourth.leekm@cnu.ac.kr

\section{Extended Abstract}

Recently, a lot of earthquakes are occurring around the worlds. Though South Korea was classified with the low to moderate seismic region before, social disquiet is increasing by occurring with Gyeongju earthquake of a 5.8 magnitude. Therefore, the interest about seismic reinforcement of the existing structures is growing in Korea. Especially, seismic reinforcement of school structures built in 80 s is essential for child's life and property. Although there are many seismic reinforcement methods, it is known for that chevron bracing system is the most effective. The chevron bracing system improves the seismic performance of existing structures by increasing the strength, stiffness, and ductile capacity. In case of chevron bracing system, the external appearance of reinforced structures is poor compared with other reinforced system. However, it is relatively excellent when compared the seismic performance, constructability, and economy of other reinforced systems. However, the seismic reinforcement design method of chevron bracing system was not systematized in Korea. Therefore, in this study, 1/2 scale experimental study was conducted to evaluate the seismic performance of existing structure reinforced by chevron bracing system, and to systematize the seismic reinforcement design method of existing structure through tests.

The $1 / 2$ scale specimens with 1 bay 1 story RC frames were fabricated by the 80 s standard school drawing in Korea. Total 3 specimens were designed with standard school drawing and current structural codes, the base specimen indicated the existing structure of standard school drawing. Another specimen was reinforced by chevron bracing system with box member having 50mm cross-section to aim the enhancement 2 times stiffness of existing frames. The other specimen was designed to aim the enhancement 3 times stiffness of existing specimen reinforced by chevron bracing system having 100 $\mathrm{mm}$ of box cross-section. The cyclic test was conducted to evaluate the seismic performance of all specimens.

As a result of experimental study, the stiffness of two specimens reinforced by chevron bracing system increased compared to existing frames without reinforcement. The stiffness of each reinforced specimens was increased to up to design goal. The ductile index of reinforced specimen with $50 \mathrm{~mm}$ box cross-section was increased $39 \%$ to compare existing frame specimen. Also, the ductility capacity of specimen reinforced by $100 \mathrm{~mm}$ box cross-section was increased about $50 \%$ compared to base specimen. The failure mechanism of reinforced specimens occurred in order of steel bracing yielding, steel bracing buckling and failure, and RC frames failure. For this reason, the strength and stiffness of specimens with steel chevron bracing system was increased.

Generally, when the chevron bracing system was reinforced at existing RC frames, the strength and stiffness of reinforced frames was increased. However, the additional studies were needed for specific reinforcement method to satisfy target performance level. Later, the seismic reinforcement design method about chevron bracing system was reasonably and economically made based on these experimental results and additional studies.

\section{Acknowledgements}

This research was supported by Mid-career Researcher Program through National Research Foundation of Korea (NRF) funded by the Ministry of Science, ICT and Future Planning (grant number: 2015R1A2A2A01006765). Participants in the research were sponsored by the BK21 Plus project. 


\section{References}

[1] AISC, "Seismic Provisions for Structural Steel Buildings," American Institute of Steel Construction, 2012.

[2] R. Ozcelik, "Seismic upgrading of reinforced concrete frames with structural steel elements," Ph.D. dissertation, Dept. Civil Eng., Middle East Tech. Univ., Ankara, Turkey, 2011. 